\title{
Chapter 19 \\ Future Directions: Cultural Competence and the Higher Education Sector
}

\author{
Jack Frawley, Gabrielle Russell, and Juanita Sherwood
}

\section{Introduction}

In one sense or another, the chapters in this book have all acknowledged that cultural competence is a set of behaviours, attitudes and/or policies that come together in the higher education sector or among professional and academic staff, and students enabling them to operate efficiently in intercultural contexts (Cross, Bazron, Dennis, \& Isaacs, 1989). There is also acknowledgement that in the Australian context, cultural competence is built on an Indigenous foundation that includes the three domains of knowing, doing and being, where knowing is about knowing and understanding history, culture, customs and beliefs; doing is culturally appropriate action and behaviour; and being is about awareness, authenticity and openness to examining own values and beliefs (Martin, 2003). Engagement in a culturally competent setting requires values-driven participation, which has a moral dimension with a focus on and commitment to ethics, moral purpose, values and beliefs, the appreciation of diversity and the establishment of authentic relationships.

Universities Australia (UA), the peak body representing Australian universities, developed the Indigenous Cultural Competency project as a key source of guidance and direction in informing the case for cultural competence within the Australian higher education sector. UA recommends making cultural competence in universities all encompassing, including in research practice, teaching and learning methodologies, and employment practices, and sees the role of universities as agents of change, committed to a social justice agenda. As a result, education is seen as the foundation for the practice of self-determination and achievement of social justice and Indigenous equality (UA, 2011).

J. Frawley $(\bowtie) \cdot$ G. Russell

National Centre for Cultural Competence, The University of Sydney, Sydney, NSW, Australia e-mail: Jack.Frawley@ sydney.edu.au

\section{J. Sherwood}

Faculty of Medicine and Health, The University of Sydney, Sydney, NSW, Australia

J. Frawley et al. (eds.), Cultural Competence and the Higher Education Sector, https://doi.org/10.1007/978-981-15-5362-2_19 
University Australia's project on cultural competence aimed to provide the Australian higher education sector with a best practice structure that included the theoretical and practical instruments needed to incorporate Indigenous cultural competence at a systems level (UA, 2011). The project identified five themesgovernance and management; teaching and learning; Indigenous research; human resources; community engagement - and these themes are used to provide some thoughts about future directions.

\section{Governance and Management}

University governance systems that have significant participation of Indigenous employees in decision-making in at least their vertical framework have a much better opportunity of success in all fields of Indigenous activities, including student results (UA, 2011). For this, the vision of change to be realised within the academy requires leadership that is geared towards a socially just and equitable system. This creates an opportunity for further research that has a focus on an audit of existing leadership policies, strategies and initiatives, and examples of best practice across the higher education sector from which best practice principles can be distilled. For Indigenous leaders working at the governance and management levels, research that explores the challenges of merging workplace and Indigenous expectations may provide valuable insights (Doyle \& Hungerford, this volume).

\section{Teaching and Learning}

It would be difficult to argue from a historical standpoint that the teaching on Australian Indigenous studies and the including of Indigenous knowledges (IKs) and perspective in higher education curriculum has been adequately addressed, although in more recent times there has been a shift towards addressing this imbalance. The Review of Australian Higher Education stated that:

\footnotetext{
Indigenous involvement in higher education is not only about student participation and the employment of Indigenous staff. It is also about what is valued as knowledge in the academy. Indigenous students and staff have unique knowledge and understandings which must be brought into the curriculum for all students and must inform research and scholarship. (Bradley, Noonan, Nugent, \& Scales, 2008, p. 32)
}

This also calls for a culturally responsive pedagogy (Willsher and Oldfield, this volume) that develops appropriate content and learning resources, teaching strategies and assessment methods, for not just Indigenous students but all students, to ensure academic development and engagement with tasks. In essence, there is an ongoing requirement for the co-generation of knowledge that challenges the academy to be more inclusive of intercultural perspectives within and across disciplines. The aim 
here is to produce graduates who are invested with sophisticated understanding, abilities and characteristics of cultural competence through achieving embedded formal graduate qualities.

\section{Indigenous Research}

Research that is culturally responsive relies on establishing processes to guarantee that the research is culturally secure and beneficial to Indigenous people and the community from which the study is taken (UA, 2011). This calls on the higher education sector to develop processes, rules and procedures with Indigenous staff, students and communities to guarantee that research is culturally and methodologically sound. Culturally competent research depends on an organisational setting that embraces Indigenous knowledges and practice in creative and more inclusive ways. At a university level, a whole-of-institution approach should include a commitment to revise and assess student and staff capacity to implement culturally competent research, with a focus on engaging communities as co-partners in the research enterprise. This localised model of research is suited to the context and community of interest and, some argue, is a methodologically sound approach (Doyle and Hungerford, this volume).

\section{Human Resources}

Indigenous people are under-represented at all levels as staff of Australian universities. This under-representation gives an adverse signal to both Indigenous and nonIndigenous students and staff about Indigenous people's place in higher education. It also undermines other approaches directed at engaging Indigenous people and their communities in the higher education sector (UA, 2011). Smith and Robertson (this volume) found in their research that recruitment, retention and professional advancement were all significant variables in the development and maintenance of qualified Indigenous higher education staff across all sectors of the university and that employment of Indigenous people in leadership and management positions was important.

Nguyen and Hartz (this volume) extend the argument for cultural competence to the employability of international students and identify the aspects of cultural competence that can allow global learners to improve their employability when searching for job in Australia. These aspects include understanding, social projects, flexibility, the capacity to recognise various worldviews, emotional stability and self-reflection.

From a human resources perspective, in the context of employment and employability, there is a need for ongoing work in developing induction processes which include cultural competence training for all new staff. 


\section{Community Engagement}

Significant involvement with Indigenous groups and organisations outside the university should be the main pathway for constructing Indigenous cultural competence within the higher education sector that encompasses governance and management, teaching and learning, research and human resources. Universities also have a significant part to play in disseminating cultural competence practices and attitudes towards non-Indigenous groups (UA, 2011). At the heart of engagement is partnerships:

Engagement requires partnerships. Equitable partnership approaches involve individuals, community members, organisational representatives, and researchers in all aspects of community engagement. Partners contribute their expertise and share responsibilities and ownership to increase understanding and incorporate the knowledge gained with the engagement. Partnership approaches build on strengths and resources within the community; facilitate collaborative, equitable involvement of all partners; integrate knowledge and action for the mutual benefit of all partners; and disseminate program findings and knowledge gained to all. (Frawley, Larkin, \& Smith, 2017, p. 8)

Engagement also requires conversations where there is constant change and fluidity, providing room for fresh understanding and culture formations constructed around confidence, reciprocity, appreciation and regard (Davis, this volume). UA (2011) recommends that mechanisms, cultural protocols and codes of conduct need to be established to provide the higher education sector with a guide for engagement with Indigenous people, communities and organisations.

\section{Conclusion}

Developing cultural competence in higher education needs extensive organisational policies that place universities as agents of change and transformation. This book has drawn together academics, policy-makers, practitioners and professionals who have provided perspectives, understandings and knowledge of strategies and practices related to cultural competence in higher education. The overarching theme throughout the book has been cultural competence and its interaction with the higher education sector through a range of multidisciplinary and interdisciplinary perspectives, and descriptions of applied strategies and practice. While there seems to be a consensus that cultural competence as a concept eludes a unifying definition, there is general agreement that cultural competence is a journey which is ambitious, cumulative and lifelong. This book represents a map of sorts-not a static map, but one that is in a state of change as new features are added and modifications made. And as a map, it will assist with navigation and direction. 


\section{References}

Bradley, D., Noonan, P., Nugent, H., \& Scales, B. (2008). Review of Australian higher education. Final report. Canberra, Australia: Commonwealth of Australia.

Cross, T. L., Bazron, B. J., Dennis, K. W., \& Isaacs, M. R. (1989). Towards a culturally competent system of care: A monograph on effective services for minority children who are severely emotionally disturbed. Washington, DC: Child and Adolescent Service System Program Technical Assistance Center, Georgetown University Child Development Center.

Frawley, J., Larkin, S., \& Smith, J. A. (2017). Indigenous pathways and transitions into higher education: An introduction. In J. Frawley, S. Larkin, \& J. A. Smith (Eds.), Indigenous pathways, transitions and participation in higher education: From policy to practice. Singapore: Springer Open.

Martin, K. (2003). Ways of knowing, being and doing: A theoretical framework and methods for Indigenous and indigenist research. In K. McWillian, P. Stephenson, \& G. Thompson (Eds.), Voicing dissent (pp. 203-257). Brisbane: University of Queensland Press.

Universities Australia. (2011). Guiding principles for developing Indigenous cultural competency in Australian universities. Canberra: Universities Australia.

Jack Frawley has a national and international profile as researcher, writer, and educator in the areas of intercultural studies, education, history, leadership studies, and the arts. He has worked extensively as a consultant for program evaluation, research, and education-related projects, in Australian Aboriginal communities as well as in the South Pacific and Southeast Asia, especially in Cambodia.

Gabrielle Russell is the Acting Director of the National Centre for Cultural Competence, The University of Sydney. Her diverse experience has been gained working in non-government organisations, politics, business, church organisations, and higher education. She is particularly interested in how to develop cultural competence from a non-Indigenous perspective and, in particular, how to facilitate a deeper understanding of transformative ways to learn and work together. Gabrielle's teaching and research interests include race and racism, critical pedagogies, service learning, and cultural competence.

Juanita Sherwood is a Wiradjuri woman from New South Wales. She has over 25 years of experience in Indigenous health and education, community-based research methodologies, and decolonisation strategies that improve health and healing outcomes for Indigenous people. She is currently the Associate Dean (Indigenous) for the Faculty of Medicine and Health at The University of Sydney. 
Open Access This chapter is licensed under the terms of the Creative Commons Attribution 4.0 International License (http://creativecommons.org/licenses/by/4.0/), which permits use, sharing, adaptation, distribution and reproduction in any medium or format, as long as you give appropriate credit to the original author(s) and the source, provide a link to the Creative Commons license and indicate if changes were made.

The images or other third party material in this chapter are included in the chapter's Creative Commons license, unless indicated otherwise in a credit line to the material. If material is not included in the chapter's Creative Commons license and your intended use is not permitted by statutory regulation or exceeds the permitted use, you will need to obtain permission directly from the copyright holder.

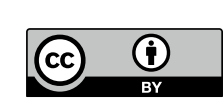

